\title{
3,4-Dihydroxyphenylacetaldehyde Is More Efficient than Dopamine in Oligomerizing and Quinonizing $\alpha$-Synuclein
}

\author{
Yunden Jinsmaa, Risa Isonaka, Yehonatan Sharabi, and David S. Goldstein \\ Autonomic Medicine Section, Clinical Neuroscience Program, Division of Intramural Research, National Institute of Neurological \\ Disorders and Stroke, National Institutes of Health, Bethesda, Maryland (Y.J., R.I., D.S.G.); and Sackler Faculty of Medicine, Tel \\ Aviv University, Tel Aviv, Israel (Y.S.)
}

Received September 4, 2019; accepted November 13, 2019

\begin{abstract}
Lewy body diseases such as Parkinson's disease involve intraneuronal deposition of the protein $\alpha$-synuclein (AS) and depletion of nigrostriatal dopamine (DA). Interactions of AS with DA oxidation products may link these neurohistopathologic and neurochemical abnormalities via two potential pathways: spontaneous oxidation of DA to dopamine-quinone and enzymatic oxidation of DA catalyzed by monoamine oxidase to form 3,4dihydroxyphenylacetaldehyde (DOPAL), which is then oxidized to DOPAL-Q. We compared these two pathways in terms of the ability of DA and DOPAL to modify AS. DOPAL was far more potent than DA both in oligomerizing and forming quinoneprotein adducts with (quinonizing) AS. The DOPAL-induced protein modifications were enhanced similarly by pro-oxidation with $\mathrm{Cu}(\mathrm{II})$ or tyrosinase and inhibited similarly by antioxidation with $\mathrm{N}$-acetylcysteine. Dopamine oxidation evoked by $\mathrm{Cu}$ (II) or tyrosinase did not quinonize AS. In cultured MO3.13 human oligodendrocytes DOPAL resulted in the formation of numerous intracellular quinoproteins that were visualized by near-infrared
\end{abstract}

spectroscopy. We conclude that of the two routes by which oxidation of DA modifies AS and other proteins the route via DOPAL is more prominent. The results support developing experimental therapeutic strategies that might mitigate deleterious modifications of proteins such as AS in Lewy body diseases by targeting DOPAL formation and oxidation.

\section{SIGNIFICANCE STATEMENT}

Interactions of the protein $\alpha$-synuclein with products of dopamine oxidation in the neuronal cytoplasm may link two hallmark abnormalities of Parkinson disease: Lewy bodies (which contain abundant AS) and nigrostriatal DA depletion (which produces the characteristic movement disorder). Of the two potential routes by which DA oxidation may alter AS and other proteins, the route via the autotoxic catecholaldehyde 3,4-dihydroxyphenylacetaldehyde is more prominent; the results support experimental therapeutic strategies targeting DOPAL formation and DOPALinduced protein modifications.

\section{Introduction}

Diseases that involve progressive central catecholaminergic neurodegeneration such as Parkinson's disease (PD) and multiple system atrophy are associated with profound putamen dopamine (DA) depletion (Hornykiewicz, 1966; Tong et al., 2004; Goldstein et al., 2015), deposition of the protein $\alpha$-synuclein (AS) in neurons in PD (Spillantini et al., 1997) and in glial cells in multiple system atrophy (Tu et al., 1998), and buildup of catecholaldehyde 3,4-dihydroxyphenylacetaldehyde (DOPAL) (Goldstein et al., 2011b, 2013, 2015). DOPAL, which is an obligate intermediate in neuronal DA metabolism, is formed from the enzymatic oxidation of cytoplasmic DA by monoamine oxidase (MAO) in the outer mitochondrial membrane. In cells and animals DOPAL is toxic (Mattammal et al., 1995; Burke et al., 2003; Panneton et al., 2010), such

This work was supported by the division of intramural research program of the National Institutes of Health National Institute of Neurologic Disorders and Stroke.

The authors have no conflicts of interest to disclose.

https://doi.org/10.1124/jpet.119.262246. that DOPAL accumulation might contribute to neuronal malfunctions and eventual loss of dopaminergic neurons (Burke et al., 2003; Goldstein et al., 2014).

An almost completely independent line of research has centered on potentially harmful effects of spontaneous oxidation of DA (Hastings, 2009; Surmeier et al., 2011; Burbulla et al., 2017; Herrera et al., 2017). DA can undergo oxidation to form dopamine-quinone (DA-Q) and then a variety of potentially neurotoxic compounds such as aminochrome (Linsenbardt et al., 2009; Paris et al., 2009; Segura-Aguilar, 2019), 5-S-cysteinyldopamine (Montine et al., 1997; BadilloRamírez et al., 2019), and isoquinolines (Nagatsu, 1997; Storch et al., 2002).

The catecholamine autotoxicity theory imputes pathologic interactions between catecholamine oxidation products and intracellular proteins in the pathogenesis of diseases involving catecholaminergic neurodegeneration (Goldstein et al., 2014). Specifically, DOPAL oligomerizes AS (Burke et al., 2008), and oligomerized AS seems to be pathogenic (Winner et al., 2011; Deas et al., 2016; Gustafsson et al., 2017). Divalent metal cations, especially $\mathrm{Cu}(\mathrm{II})$, augment DOPAL-induced AS

ABBREVIATIONS: AS, $\alpha$-synuclein; DA, dopamine; DA-Q, dopamine-quinone; DOPAL, 3,4-dihydroxyphenylacetaldehyde; DOPAL-Q, 3,4dihydroxyphenylacetaldehyde/quinone; MAO, monoamine oxidase; NAC, $N$-acetylcysteine; nIRF, near-infrared fluorescence; PD, Parkinson's disease; Tyr, tyrosinase; WT, wild type. 
A nIFR (DOPAL)

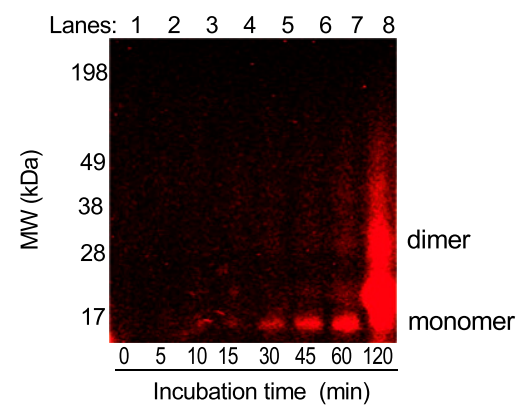

C

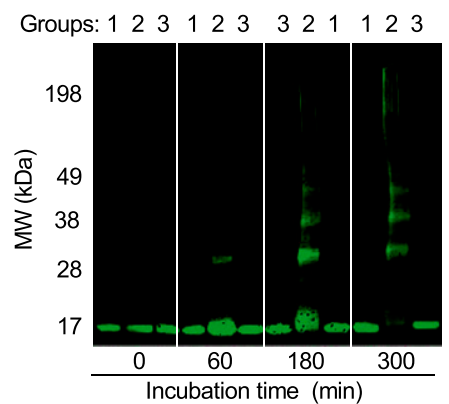

\section{Western Blotting (DOPAL)}

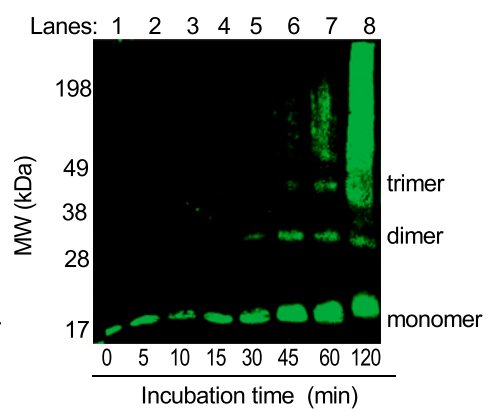

B nIRF (DOPAL vs DA)

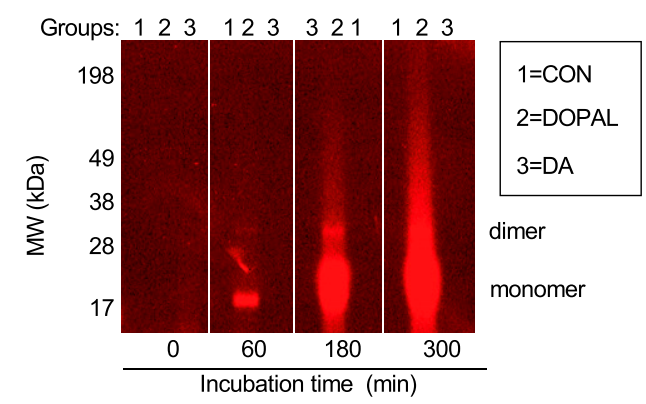

D Protein Staining (DOPAL vs DA)

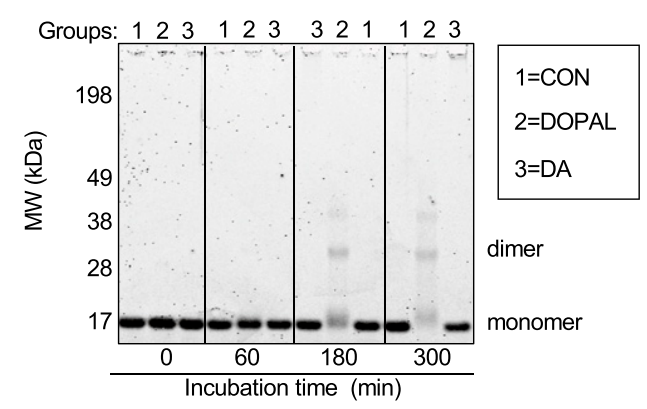

Fig. 1. Time courses of DOPAL and DA effects on AS quinonization and oligomerization. (A) AS (3 $\mu \mathrm{M})$ was incubated with DOPAL or DA (30 $\mu \mathrm{M}$ each) at $37^{\circ} \mathrm{C}$ and samples were taken after 120 minutes (A) and 300 minutes (B) of incubation. (A and B) Quinonized AS was detected by nIRF spectroscopy (red). (A and C) Oligomerized AS was detected by western blotting (green). (D) Protein staining was used to demonstrate decreased AS monomer during incubation of AS with DOPAL. Lanes = order of the gel lanes, Groups: $1=$ AS alone as a control (CON), $2=$ DOPAL, $3=$ DA. DOPAL time dependently increased AS quinonization and oligomerization, whereas DA did not elicit AS quinonization and produced a slight smear of high molecular weight AS.

oligomerization (Jinsmaa et al., 2014). DOPAL also forms covalent quinone adducts (quinonizes) with many PD-related proteins, including AS (Jinsmaa et al., 2018). Quinonization may interfere with the functions of these proteins, and thereby with numerous intracellular processes. In particular, it has been reported that compounds formed after DA oxidation to DA-Q evoke mitochondrial dysfunction (Jana et al., 2011). Oxidized DA also can interact with AS (Hasegawa et al., 2006). DA can promote the formation of AS oligomers (Leong et al., 2009; Lee et al., 2011; Saha et al., 2018). Moreover, aminochrome and 5,6-dihydroxyindole, which are products of DA oxidation, can oligomerize AS (Pham et al., 2009; Muñoz et al., 2015; Huenchuguala et al., 2019).

The literature on DA oxidation and synucleinopathy has generally overlooked DOPAL (Asanuma et al., 2003; Mazzulli et al., 2006; Leong et al., 2009; Burbulla et al., 2017; Mor et al., 2017, 2019; Segura-Aguilar, 2017), and the literature on DOPAL and synucleinopathy has generally overlooked DA-Q (Burke et al., 2008; Follmer et al., 2015; Jinsmaa et al., 2018; Cagle et al., 2019). In the few studies where DOPAL and DA have been compared directly in terms of oligomerizing AS, DOPAL has been found to be more potent (Burke et al., 2008; Jinsmaa et al., 2014, 2018). Whether oxidation of DA results in quinonization of AS or intracellular proteins via routes other than DOPAL has not been assessed.

The overall purpose of the present experiments was to compare DOPAL and DA in terms of: 1) AS oligomerization and quinonization in $1.5 \mathrm{ml}$ Eppendorf tube experiments; 2) enhancing effects of $\mathrm{Cu}$ (II) (Jinsmaa et al., 2014; Dell'Acqua et al., 2017) and mitigating effects of antioxidation with
$\mathrm{N}$-acetylcysteine (NAC) (Banerjee et al., 2014; Anderson et al., 2016; Goldstein et al., 2017a; Jinsmaa et al., 2018); and 3) quinonization of intracellular proteins in cultured cells (Banerjee et al., 2014; Jinsmaa et al., 2018). From these comparisons one would anticipate improved targeting in disease-modification experimental therapeutic trials.

For the cellular experiments we used human MO3.13 oligodendrocytes. Studying MO3.13 oligodendrocytes is relevant to multiple system atrophy, which is a synucleinopathy that can closely resemble PD clinically but features AS deposition in the cytoplasm of glial cells-especially in oligodendrocytes (Tu et al., 1998; Wakabayashi et al., 1998; Pukass and Richter-Landsberg, 2014). DOPAL is known to aggregate AS in MO3.13 cells (Jinsmaa et al., 2018), but whether DOPAL evokes the formation of intracellular quinoproteins is still unknown.

\section{Materials and Methods}

Reagents and Chemicals. Human recombinant AS [wild type (WT)] was purchased from Calbiochem (La Jolla, CA). DOPAL was from obtained Santa Cruz Biotech (Dallas, TX). Mutant A53T AS, NAC, dithiothreitol, glycine, tyrosinase (Tyr), pargyline-HCl, MAO-B, saponin, and the aldehyde dehydrogenase inhibitor benomyl were obtained from Sigma-Aldrich (St. Louis, MO). The aldehyde reductase inhibitor AL-1576(spiro-(2,7-difluoro-9H-fluoren-9,4'-imidazolidine: Imirestat) was a gift from Alcon Laboratories, Fort Worth, TX. Tolcapone was obtained from Orion Pharma (Espoo, Finland). MO3.13 cells were obtained from Cellutions Biosystems Inc. (Burlington, ON, Canada). Cell culture medium was obtained from Invitrogen (Camarillo, CA). PBS and deionized ultrapure water were obtained 
A

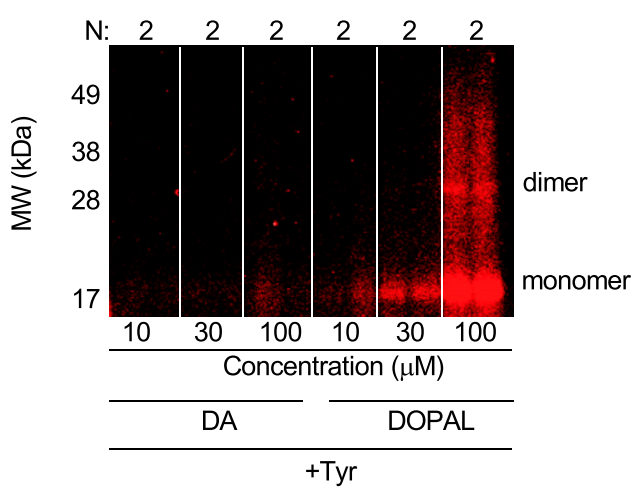

C

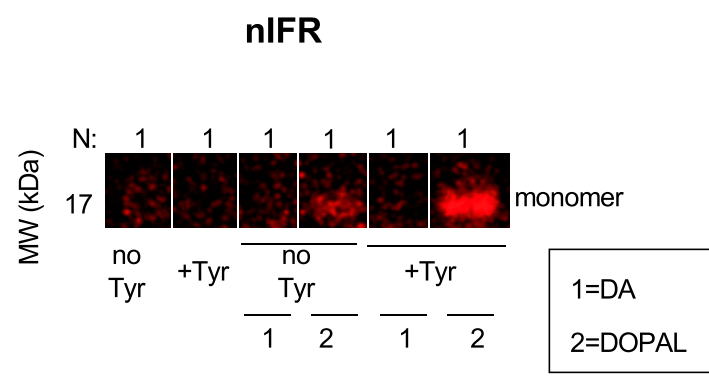

B Western Blotting

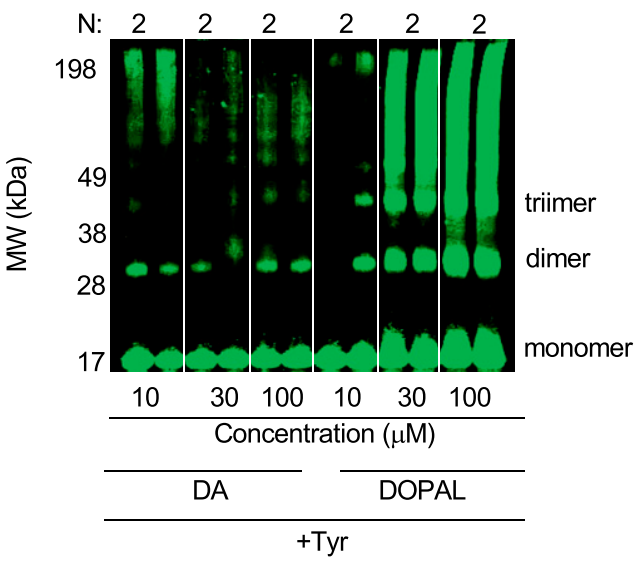

Western Blotting

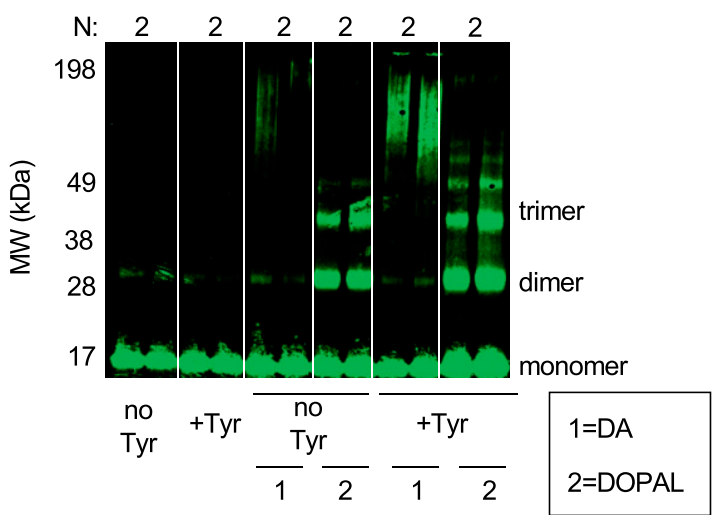

Fig. 2. Effects of enzymatic oxidation of DA and DOPAL with tyrosinase on AS quinonization and oligomerization. DA or DOPAL (30 $\mu$ M each) was incubated with tyrosinase (+Tyr) or without tyrosinase (no Tyr) for 20 minutes at room temperature and then incubated with AS (3 $\mu \mathrm{M})$ for 1 hour at $37^{\circ} \mathrm{C}$. (A and B) Concentration course of DA or DOPAL (10, 30, and $100 \mu \mathrm{M}$ each) oxidation with Tyr. (A and C) Quinonized AS was detected by nIRF spectroscopy (red). (B and D) Oligomerized AS was detected by western blotting (green). N = number of replicates; $1=\mathrm{DA} ; 2=\mathrm{DOPAL}$. Enzymatic oxidization augmented DOPAL-induced oligomerization and quinonization of AS. Incubation of AS with DA and Tyr resulted in a smear of high molecular weight AS. DA did not quinonize AS even in the setting of enzymatic oxidation by Tyr.

from KD Medical (Columbia, MD). Benomyl, (AL-1576) (spiro-(2,7difluoro-9H-fluoren-9,4'-imidazolidine) 2 ', $5^{\prime}$-dione: Imirestat), and tolcapone were dissolved in DMSO (American Bio, Natick, MA) and stored at $-20^{\circ} \mathrm{C}$. NAC, DOPAL, and DA stock solutions were prepared in ultrapure water and stored at $-20^{\circ} \mathrm{C}$.

Eppendorf Tube Experiments. Experiments in $1.5 \mathrm{ml}$ Eppendorf plastic sample tubes were done to compare DA with DOPAL in terms of oligomerization and quinonization of AS and the effects of various conditions augmenting or mitigating these actions.

The effects of treatment with DOPAL or DA on AS protein modifications were assessed by incubation of AS $(3 \mu \mathrm{M})$ with DOPAL $(30 \mu \mathrm{M})$ or DA $(30 \mu \mathrm{M})$ in $50 \mathrm{mM}$ phosphate buffer $(\mathrm{pH} 7.4)$ at $37^{\circ} \mathrm{C}$ in a water bath for 2 or 5 hours depending on the experiment. Samples $(15 \mu \mathrm{l})$ were taken at different time points and heated in NuPAGE LDS Sample Buffer with $50 \mathrm{mM}$ dithiothreitol for 5 minutes at $70^{\circ} \mathrm{C}$. The reaction mixtures ( 5 or $15 \mu \mathrm{l}$ ) were then electrophoresed on NuPAGE $4 \%-12 \%$ Bis-Tris gels.

Protein modifications were detected by near-infrared fluorescence (nIRF) spectrometry (15 $\mu$ l applications to gels) and western blotting ( $5 \mu \mathrm{l}$ applications to gels). The $\mathrm{nIRF}$ signals were read with excitation wavelength $685 \mathrm{~nm}$ using an Odyssey infrared imager (Li-Cor Biosciences, Lincoln, NE) (Jinsmaa et al., 2018). For western blotting, the proteins were transferred to nitrocellulose membranes using an iBlot dry blotting system (Novex Life Technologies, ThermoFisher Scientific, Waltham, MA). AS detection was done with mouse anti-human AS antibody (1:200; Invitrogen), with the secondary antibody being goat anti-mouse IRDye 800CW (1:10,000; Abcam, Cambridge, MA), and read using the Odyssey imaging system. Protein staining was done with AcquaStain (Bulldog Bio, Portsmouth, NH). There was one experiment, with three to four replicates at each observation point (Jinsmaa et al., 2018).

The effects of enzymatic oxidation of DOPAL or DA on AS protein modifications were examined in two experiments. In one experiment, DA $(30 \mu \mathrm{M})$ and DOPAL $(30 \mu \mathrm{M})$ were kept at room temperature for 20 minutes with and without tyrosinase $(69 \mathrm{U} / \mathrm{ml})$, followed by incubation of the mixture with AS $(3 \mu \mathrm{M})$ for 1 hour. In another experiment, different concentrations of $\operatorname{DOPAL}(10,30$, and $100 \mu \mathrm{M})$ or DA $(10,30$, and $100 \mu \mathrm{M})$ were incubated with tyrosinase and then incubated with AS. Protein modifications were detected as described previously. There were two experiments, with three to four replicates at each observation point.

The effects of $\mathrm{Cu}$ (II) on AS protein modifications elicited by DOPAL and DA were studied in two experiments. In one experiment, AS $(3 \mu \mathrm{M})$ and DOPAL $(30 \mu \mathrm{M})$ were incubated with various concentrations of $\mathrm{Cu}(\mathrm{II})(1-100 \mu \mathrm{M})$ at $37^{\circ} \mathrm{C}$ in a water bath for 1 hour. Different concentrations of NAC $(100-300 \mu \mathrm{M})$ were added at the start of the incubation. There were three to four replicates. In another experiment, to compare DOPAL and DA, AS $(3 \mu \mathrm{M})$ and DOPAL $(30 \mu \mathrm{M})$ or $\mathrm{DA}(30 \mu \mathrm{M})$ were incubated with $\mathrm{Cu}(\mathrm{II})(1$ or $30 \mu \mathrm{M})$ at $37^{\circ} \mathrm{C}$ in a water bath for 1 hour. To assess the time courses of the reactions, 
A

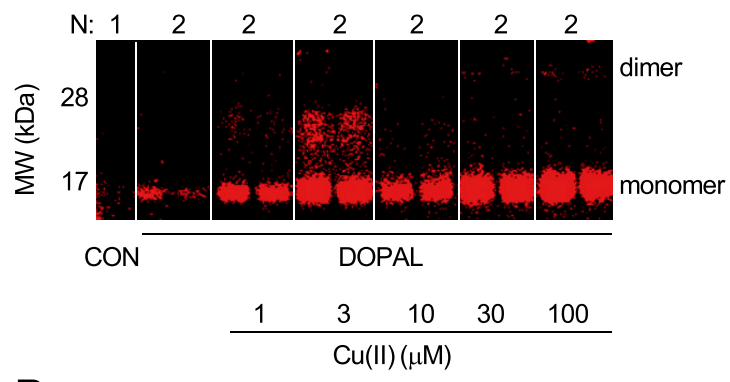

B

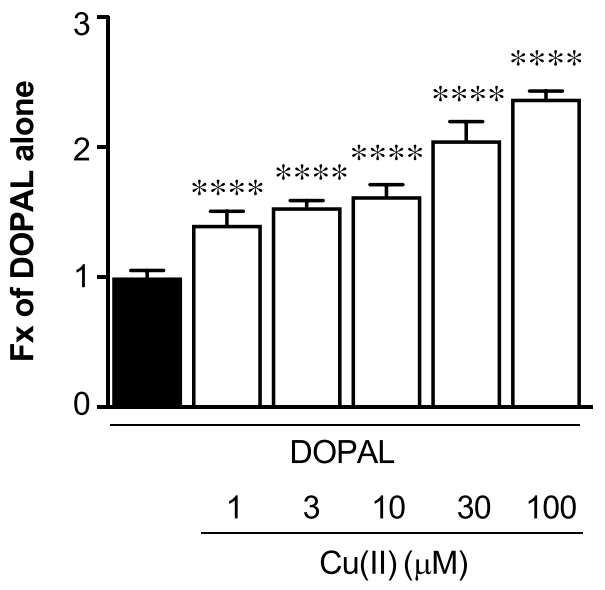

C nIFR
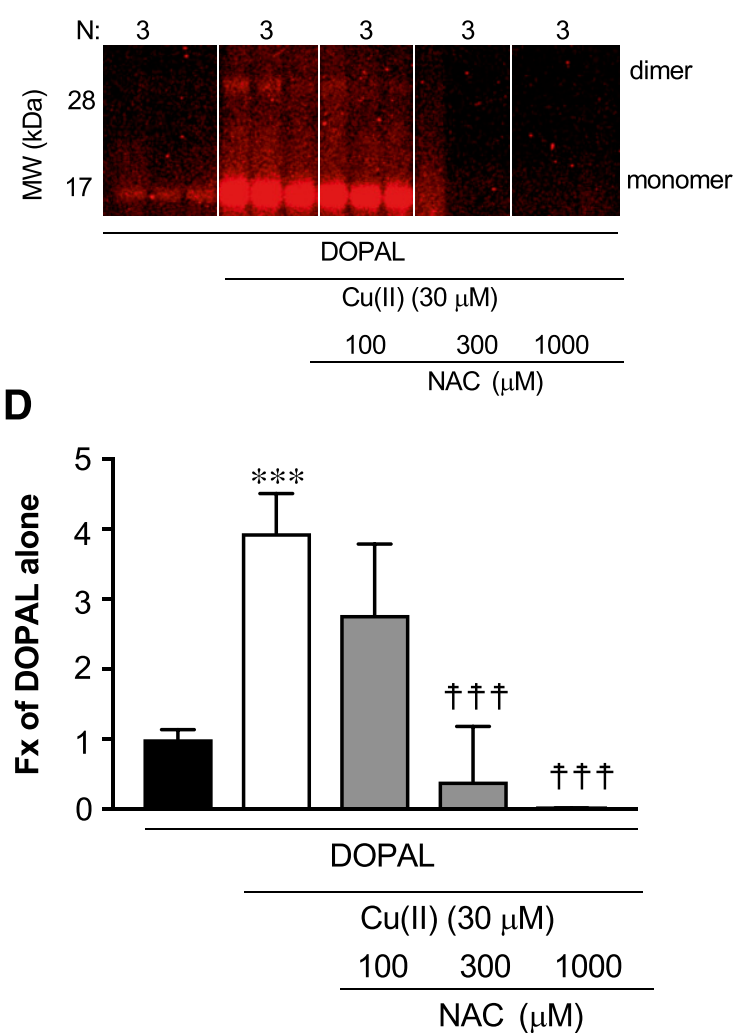

Fig. 3. Effects of $\mathrm{Cu}(\mathrm{II})$ on DOPAL-induced AS quinonization and NAC effect. (A and B) AS ( $3 \mu \mathrm{M}$ ) was incubated with $30 \mu \mathrm{M}$ DOPAL and 1-100 $\mu \mathrm{M}$ $\mathrm{Cu}$ (II) for 1 hour at $37^{\circ} \mathrm{C}$. (C and D) AS was incubated with DOPAL and $30 \mu \mathrm{M} \mathrm{Cu}$ (II) and 0-1000 $\mu \mathrm{M}$ NAC for 1 hour at $37^{\circ} \mathrm{C}$. Quinonized AS was detected by nIRF spectroscopy (red). N, number of replicates; Fx, fractions of integrated intensities of AS monomers compared with DOPAL alone. Statistical analyses were done by one-way ANOVA with Dunnett's post-hoc test. Mean values are expressed as \pm S.E.M. $* * * * P<0.0001, * * * P<0.001$ compared with DOPAL alone; ${ }^{+\uparrow} P<0.001$ vs. DOPAL + Cu(II) compared with no NAC. Cu(II) concentration dependently augmented DOPAL-induced AS quinonization and oligomerization. NAC attenuated this effect.

samples $(15 \mu \mathrm{l})$ were taken at different time points $(0,5,15,30,45$, and 60 minutes). There were three to four replicates. Protein modifications were detected as described previously.

Human WT and A53T mutant forms of AS were compared in terms of effects of DOPAL $+\mathrm{Cu}$ (II) on AS oligomerization and quinonization. Each protein $(3 \mu \mathrm{M})$ was incubated with DOPAL $(30 \mu \mathrm{M})$ and $\mathrm{Cu}(\mathrm{II})$ $(30 \mu \mathrm{M})$ at $37^{\circ} \mathrm{C}$ in a water bath for 1 hour. Protein modifications were detected as described previously. There was one experiment, with three to four replicates.

Cellular Experiments on DOPAL- and DA-Induced Protein Modifications. Using nIRF spectroscopy and microscopy we compared DOPAL and DA in terms of quinonization of intracellular proteins in MO3.13 human oligodendrocytes. The cells were cultured in high-glucose Dulbecco's modified Eagle's medium containing $10 \%$ fetal calf serum. MO3.13 cells were plated in 12-well plates/slide $\left(1.5 \times 10^{5}\right.$ cells/well $)$ or two-well plates/slides $\left(8 \times 10^{4}\right.$ cells/well $)$. The cells were incubated for 24 hours with $10 \mu \mathrm{M}$ tolcapone added to the medium to block catechol- $O$-methyltransferase. On the day of the acute experiments the medium used was Dulbecco's modified Eagle's medium containing $10 \mu \mathrm{M}$ each of tolcapone and benomyl and $1 \mu \mathrm{M}$ AL-1576. The cells were then further exposed to other compounds as described subsequently.

To assess $\mathrm{Cu}$ (II) effects on DOPAL-quinonized proteins in MO3.13 cells, after 24 hours of incubation with medium containing tolcapone the cells were treated with DOPAL $(100 \mu \mathrm{M})$ and $\mathrm{Cu}$ (II) (10 and $30 \mu \mathrm{M}$ ) for 5 hours at $37^{\circ} \mathrm{C}$ in a $\mathrm{CO}_{2}$ incubator. The cells were then lysed with radioimmunoprecipitation assay buffer (Millipore, Temecula, CA) containing one tablet per $10 \mathrm{ml}$ of cOmplete Mini Protease
Inhibitor (Roche Diagnostics, Indianapolis, IN). The proteins (15 $\mu \mathrm{l})$ were heated in NuPAGE LDS Sample Buffer with $50 \mathrm{mM}$ dithiothreitol for 5 minutes at $70^{\circ} \mathrm{C}$. The reaction mixtures were then electrophoresed on NuPAGE $4 \%-12 \%$ Bis-Tris gels, and the nIRF signals were quantified using the Odyssey infrared imaging system as described previously (Jinsmaa et al., 2018).

To assess the effects of NAC on DOPAL-quinonized intracellular proteins, MO3.13 cells were exposed to DOPAL $+\mathrm{Cu}(\mathrm{II})(30 \mu \mathrm{M}$ each $)$ with different concentrations of NAC $(10,30,100$, and $300 \mu \mathrm{M})$ for 5 hours at $37^{\circ} \mathrm{C}$ in a $\mathrm{CO}_{2}$ incubator. The cells were then lysed and processed as described previously.

To visualize intracellular DOPAL-induced quinoproteins in MO3.13 oligodendrocytes, the cells were exposed to DOPAL (10, 30, and $100 \mu \mathrm{M})$ for 5 hours in the presence of $30 \mu \mathrm{M} \mathrm{Cu}$ (II). The cells were then fixed with ice-cold methanol for 20 minutes and washed with cold PBS three times. Permeabilization and blocking were done with 15 drops/slide of the TrueBlack IF Background Suppressor System (Biotium Inc, Fremont, CA) for 15 minutes. Slides were then incubated with human anti-tubulin antibody (1:1500; Abcam) overnight at $4^{\circ} \mathrm{C}$, followed by incubation with the secondary antibody Alexa FluorR 488 goat anti-mouse antibody (1:500; Molecular Probes, Thermo Scientific) for 1 hour at room temperature. Cells were also stained for 4,6diamidino-2-phenylindole (1:2000; Abcam) to visualize cell nuclei. Images were obtained using a Zeiss 880 confocal microscope. nIRF was detected at $587-686 \mathrm{~nm}$. There were three experiments with one set of observations.

Data Analysis and Statistics. Mean values were expressed \pm S.E.M.. Statistical analyses were done by one-way factorial analyses of 
A $1 \mu \mathrm{M} \mathrm{Cu}$ (II)

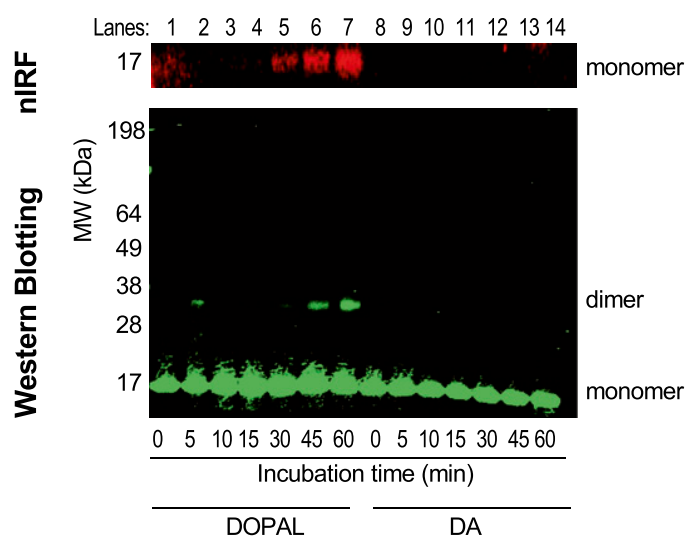

B

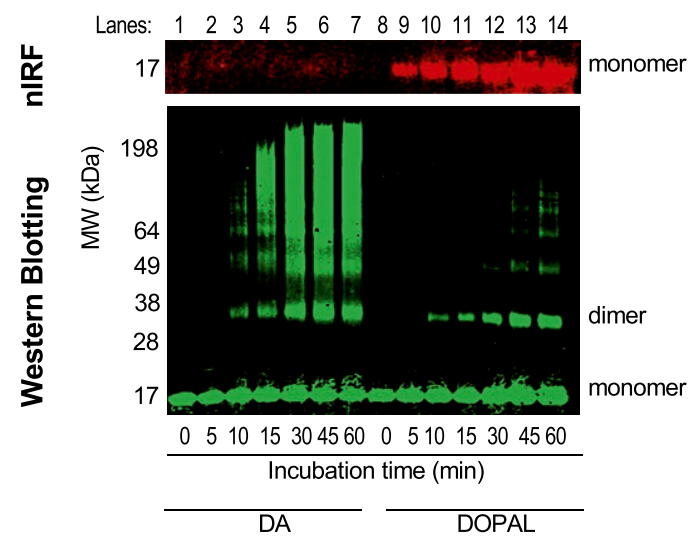

C

nIRF

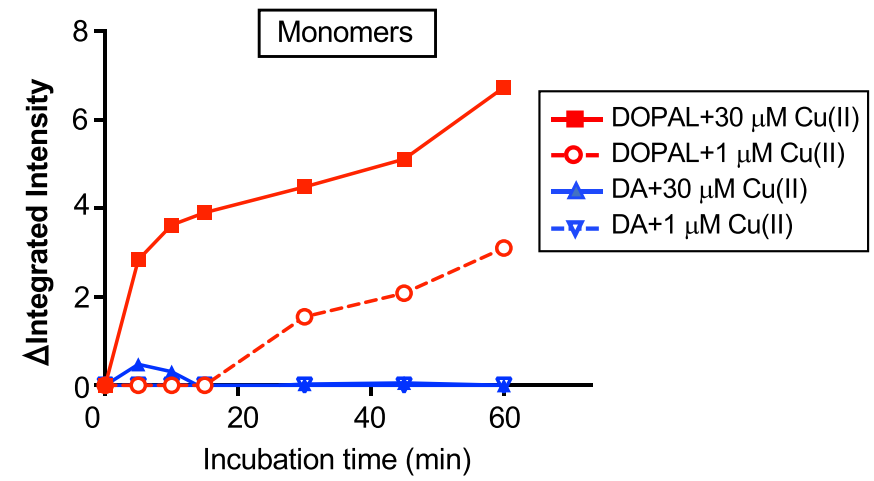

Fig. 4. Comparisons of DA- vs. DOPAL-induced AS modifications in the presence of $\mathrm{Cu}(\mathrm{II})$. (A) Incubation of AS (3 $\mu \mathrm{M})$ with $30 \mu \mathrm{M}$ each of DA and DOPAL and $1 \mu \mathrm{M} \mathrm{Cu}$ (II). (B) Incubation of AS with DA or DOPAL and $30 \mu \mathrm{M} \mathrm{Cu(II).} \mathrm{(A-C)} \mathrm{Quinonized} \mathrm{AS} \mathrm{was} \mathrm{detected} \mathrm{by} \mathrm{nIRF} \mathrm{spectroscopy} \mathrm{(red).} \mathrm{(A}$ and B) Oligomerized AS was detected by western blotting (green). $\Delta$ Integrated intensity, the difference in integrated intensity of signal at each time point minus the integrated intensity at 0 minutes; Lanes, order of the gel lanes. $\mathrm{Cu}$ (II) at $30 \mu \mathrm{M}$ accelerated and enhanced DOPAL-induced oligomerization and quinonization of AS. Incubation of $\mathrm{Cu}(\mathrm{II})(30 \mu \mathrm{M})$ with $30 \mu \mathrm{M}$ DA and AS resulted in a smear of high molecular weight AS.

variance with Dunnett's post-hoc test to compare experimental with control (or DOPAL alone) mean values (GraphPad Software, La Jolla, CA). A $t$ test was done to compare two independent groups. Statistical significance was defined as $P<0.05$.

\section{Results}

DOPAL Oligomerizes and Quinonizes AS. DOPAL time dependently quinonized and oligomerized AS (Fig. 1). AS dimer, trimer, and quinonized AS monomer were detectable after about 30 minutes of incubation (Fig. 1A) and increased further with increasing times of incubation (Fig. 1, $\mathrm{B}$ and $\mathrm{C}$ ). Oligomerization and quinonization occurred approximately concurrently. As the incubation time increased, DOPAL resulted in an intense high molecular weight smear by both western blotting and nIRF (Fig. 1, B and C). Incubation of AS with DA resulted in a small amount of AS dimer, a faint smear of high molecular weight $\mathrm{AS}$ at long incubation times, and complete absence of quinonized AS (Fig. 1, B and C). Protein staining showed that DOPAL time dependently decreased the AS monomer (Fig. 1D), indicating substantial reactivity with AS to form other compounds, whereas DA did not.

DOPAL and DA were treated with tyrosinase to catalyze oxidation of the catechols. For both DOPAL and DA the oxidation started immediately, and within 5-10 minutes of the reaction it was obvious by the change in the color of the solutions that both catechols had been oxidized (data not shown). After tyrosinase-induced oxidation of DOPAL and DA for 20 minutes, western blotting demonstrated AS oligomerization by both catechols, with DOPAL having greater potency (Fig. 2, B and D). However quinonized AS was detected only in DOPAL group (Fig. 2, A and C). Incubation of AS with tyrosinase alone was without effect (Fig. 2, C and D). The smear of high molecular weight AS noted previously was also seen when AS was incubated with DA and tyrosinase (Fig. 2, B and D); however, no detectable quinonized AS was seen even at the highest DA concentration $(100 \mu \mathrm{M})$ (Fig. 2A).

Cu(II) Enhances DOPAL-Induced AS Quinonization and Oligomerization. $\mathrm{Cu}$ (II) at concentrations as low as $1 \mu \mathrm{M}$ augmented DOPAL-induced AS quinonization compared with DOPAL alone (Figs. $3, \mathrm{~A}$ and $\mathrm{B}$ and $4, \mathrm{~A}$ and $\mathrm{C}$ ). The effects of $\mathrm{Cu}(\mathrm{II})$ were concentration dependent (Fig. 3A). At the $30 \mu \mathrm{M}$ concentration, $\mathrm{Cu}(\mathrm{II})$ enhanced and accelerated both DOPAL-induced quinonization and oligomerization of AS, with the AS dimer and quinonized AS monomer detectable in as little as 5 minutes of incubation (Figs. $3 \mathrm{~A}$ and $4, \mathrm{~B}$ and C). DA failed to produce any quinonized AS signals under the same experimental conditions (Fig. 4, B and C). The NAC concentration dependently mitigated the effects of DOPAL $+\mathrm{Cu}(\mathrm{II})$ 
(Fig. 3, C and D). Cu(II) alone did not oligomerize or quinonize AS (data not shown).

Mutant A53T AS Is More Vulnerable than WT AS to DOPAL Effects. Mutant A53T AS was more vulnerable to DOPAL + Cu(II) treatment than was WT AS (Fig. 5). Thus, for A53T AS the amount of nIRF signal with DOPAL + $\mathrm{Cu}(\mathrm{II})$ versus DOPAL alone was about twice as large as that for WT AS $(t=2.81, P=0.0049)$.

DOPAL Induces the Formation of Cellular Quinoproteins. $\mathrm{Cu}(\mathrm{II})(30 \mu \mathrm{M})$ augmented DOPAL-induced formation of cellular quinoproteins in MO3.13 oligodendrocytes (Fig. 6, A and B). No quinoproteins were detected in DAtreated cells (data not shown). NAC attenuated the formation of quinoproteins evoked by DOPAL + Cu(II) (Fig. 6, C and D).

nIRF microscopy was used to visualize intracellular catecholinduced quinoproteins (Fig. 7). DOPAL exposure resulted in the appearance of intracellular quinoproteins, in the form of myriad pinpoint spots in nuclei and as aggregates that seemed extracellular (or were remnants of dead cells). DA did not result in detectable intracellular quinoproteins (data not shown).

\section{Discussion}

It has long been suspected that DA oxidation products contribute to the pathogenesis of PD (Blaschko, 1952; Carlsson and Fornstedt, 1991; Mattammal et al., 1995; Burbulla et al., 2017), and in particular interact with AS to challenge dopaminergic neuronal homeostasis (Mazzulli et al., 2007; Goldstein et al., 2014; Mor et al., 2017, 2019). There are two general routes by which this could happen: 1 ) nonenzymatic oxidation of DA to DA-Q, with subsequent formation of DA-Q-derived compounds such as aminochrome (Linsenbardt et al., 2012; Segura-Aguilar, 2019), isoquinolines (Storch et al., 2002), and 5-S-cysteinyldopamine (Montine et al., 1997; Badillo-Ramírez et al., 2019); and 2) MAO-catalyzed enzymatic oxidation of DA to form DOPAL (Mattammal et al., 1995), with spontaneous oxidation of DOPAL to DOPAL-quinone (DOPAL-Q) (Anderson et al., 2011; Follmer et al., 2015; Jinsmaa et al., 2018) (see the Visual Abstract). These two routes have been studied almost completely separately by different research groups. Here, we comprehensively compared DOPAL with DA in terms of oligomerizing and quinonizing AS. Both types of protein modifications may be deleterious (Jana et al., 2011; Winner et al., 2011).

DOPAL Is the Main Mediator of DA-Dependent AS Oligomerization and Quinonization. The present results confirm previous reports that DOPAL is more potent than DA in oligomerizing AS (Burke et al., 2008; Jinsmaa et al., 2014). A major new finding is that, unlike DOPAL, DA does not quinonize AS even in the setting of oxidation of DA by $\mathrm{Cu}$ (II) or tyrosinase. The differences in potencies of DOPAL and DA in oligomerizing and quinonizing AS may be explained by their different chemical structures (Rees et al., 2009); whereas DA has a terminal amine group, DOPAL has a reactive aldehyde group that can bind covalently to lysine residues (Anderson et al., 2016), which are abundant in the AS molecule (Rees et al., 2009; Follmer et al., 2015; Plotegher et al., 2017). Occupation of lysine residues completely prevents DOPAL-induced oligomerization and quinonization of AS (Jinsmaa et al., 2018).

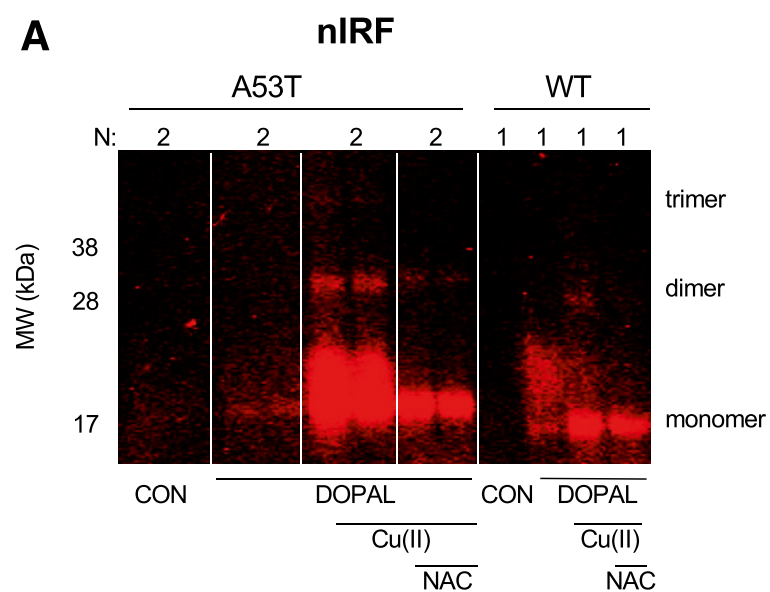

B

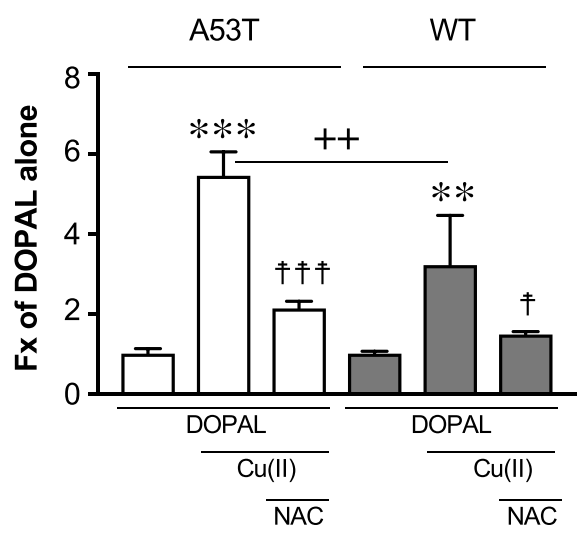

Fig. 5. (A and B) DOPAL-induced quinonization of mutant A53T vs. WT AS. WT or A53T mutant AS $(3 \mu \mathrm{M})$ was incubated with $30 \mu \mathrm{M}$ each of DOPAL and $\mathrm{Cu}(\mathrm{II})$ (with or without) or $300 \mu \mathrm{M}$ NAC (with or without) for 1 hour at $37^{\circ} \mathrm{C}$. Quinonized AS was detected by nIRF spectroscopy. Fx, fractions of integrated intensities of AS monomers compared with DOPAL alone; N, number of replicates. Statistical analyses were done by one-way ANOVA with Dunnett's post-hoc test. Mean values are expressed as \pm S.E.M. $* * * P<0.001 ; * * P<0.01$ compared with DOPAL alone; ${ }^{\dagger+\uparrow} P<$ $0.001 ;{ }^{\dagger \dagger} P<0.05$ compared with no NAC; ${ }^{++} P<0.01$ for A53T compared with WT. DOPAL quinonized both A53T and WT AS, with about twice as large an effect on A53T AS. The enhancing effects were attenuated by NAC.

DA and especially DOPAL incubation resulted in the formation of AS oligomers in discrete bands at low molecular weights and poorly defined AS smears at high molecular weights (e.g., Figs. 1C and 2, B and D). Since antioxidation with NAC mitigated these AS modifications, the results raise the possibility that oxidation products of DOPAL and DA can polymerize (Lee et al., 2007) and bind to AS, resulting in a large variety of high molecular weight forms of the bound AS. AS oligomers linked by DOPAL condensation products (Werner-Allen et al., 2016, 2017, 2018) may also polymerize. These possibilities are not mutually exclusive, and the present data cannot distinguish between them. Since AS oligomerization and quinonization occurred approximately simultaneously, we also cannot draw inferences about the relationship between quinonization and oligomerization of AS.

Because of the novelty of the discovery that DOPAL induces quinonization of numerous intracellular proteins, there is relatively scant literature about how this happens. Citraconic acid, which occupies lysine residues, prevents DOPAL-induced quinonization of AS (Jinsmaa et al., 2018). This indicates that 
A

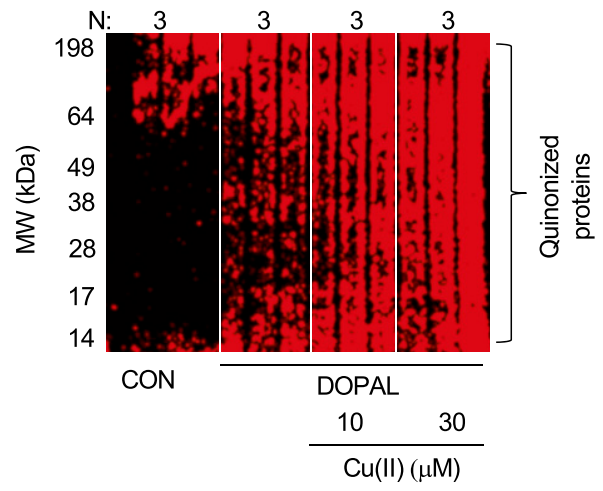

B

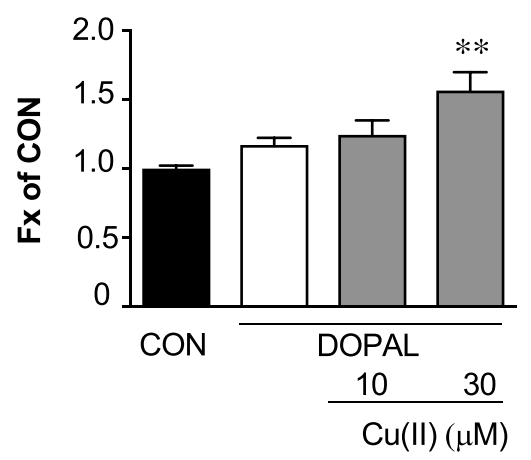

C nIRF

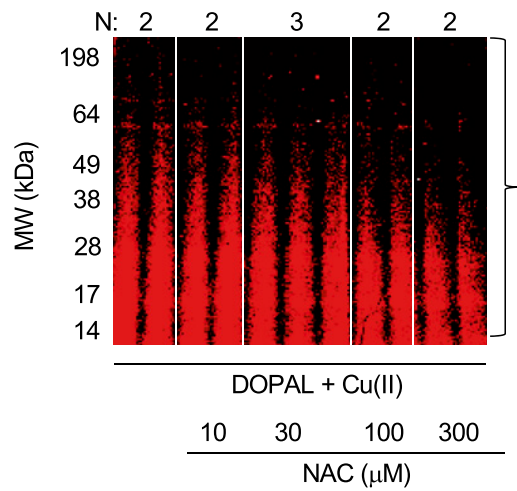

Fig. 6. DOPAL-induced quinonization of intracellular proteins in MO3.13 cells and NAC effect. (A and B) MO3.13 cells (1.5 $\times$ $10^{5}$ cells/well) were exposed to DOPAL $(100 \mu \mathrm{M})$ or DOPAL + $\mathrm{Cu}(\mathrm{II})(10$ and $30 \mu \mathrm{M})$ for 24 hours and then lysed in radioimmunoprecipitation assay buffer with protease inhibitors. (C and D) MO3.13 cells were exposed to DOPAL and $30 \mu \mathrm{M} \mathrm{Cu}$ (II), with NAC $(0-300 \mu \mathrm{M})$ added at the start of incubation. DOPAL-quinonized proteins were detected and quantified by nIRF spectroscopy (red). Fx, fractions of integrated intensities of each column compared with CON (B) or DOPAL alone (D) groups normalized to the protein of each lanes. $\mathrm{N}$, number of replicates. Statistical analyses were done by one-way ANOVA with Dunnett's post-hoc test. Mean values are expressed as \pm S.E.M. ${ }^{* *} P<0.001$

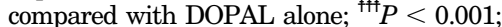
${ }^{{ }^{\#} P}<0.01$ compared with no NAC. $\mathrm{Cu}(\mathrm{II})$ augmented DOPAL-induced quinonization of intracellular proteins and NAC attenuated these effects. the site of the quinonization is lysines, which are relatively abundant in the AS molecule. $N$-acetylcysteine inhibits DOPALinduced quinonization of AS (Jinsmaa et al., 2018), consistent with the dependence of the quinonization on oxidation of DOPAL to DOPAL-Q. Since dopamine and dopamine-related catechols do not quinonize proteins nearly as potently as DOPAL, it seems likely that DOPAL-induced protein quinonization results from the reaction of the aldehyde with the amines of the lysines in AS. Whether DOPAL-Q is actually incorporated in the molecule has not yet been determined. This could be addressed by experiments using tracer-labeled DOPAL. We also do not know whether quinonization is a step in the oligomerization of AS, since the present experiments indicated approximately simultaneous quinonization and oligomerization of AS by DOPAL. Cu(II) accentuates DOPAL- and DA-induced protein modifications.

The possible roles of copper and copper-protein interactions with AS in PD pathogenesis are gaining increasing research attention (Montes et al., 2014; Saha et al., 2018). We reported previously that antioxidation with NAC prevents the augmenting effect of $\mathrm{Cu}(\mathrm{II})$ on DOPAL-induced AS oligomerization (Jinsmaa et al., 2018). Here, we report analogous enhancement by $\mathrm{Cu}(\mathrm{II})$ of DOPAL-induced quinonization of AS and mitigation of this enhancement by NAC. As part of
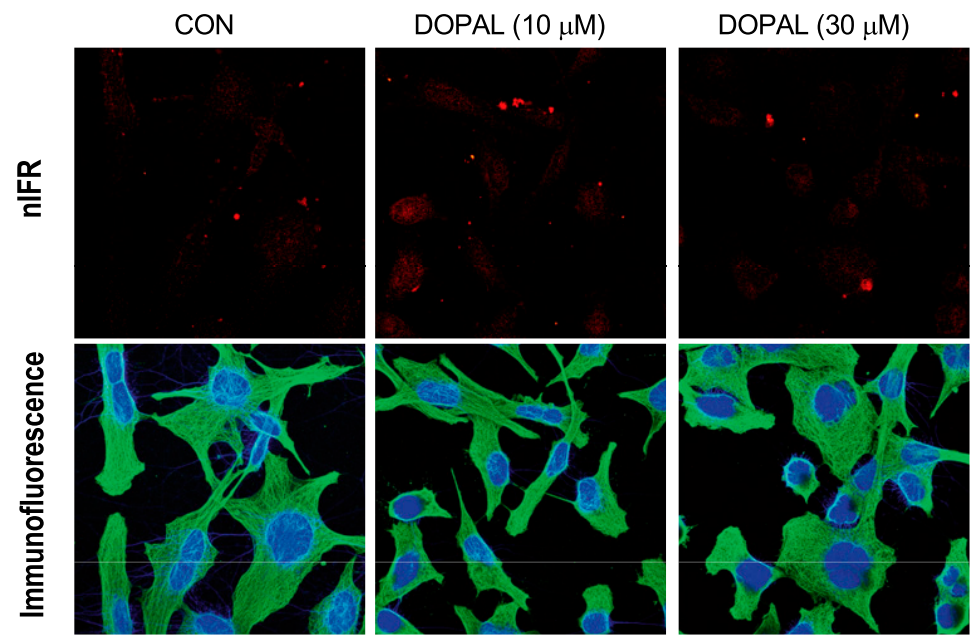

DOPAL $(100 \mu \mathrm{M})$

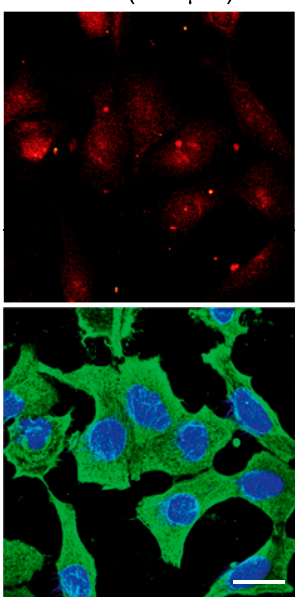

Fig. 7. Visualization of intracellular DOPALinduced quinoproteins. MO3.13 cells were cultured in slide chambers $\left(8 \times 10^{4}\right.$ cells/slides) for 24 hours and treated with $\mathrm{Cu}(\mathrm{II})(30 \mu \mathrm{M})$ and $0-100 \mu \mathrm{M}$ DOPAL for 5 hours. Cells were then stained with 4,6diamidino-2-phenylindole (1:2000) (blue) and human tubulin antibody (1:1500) (green). Immunofluorescence and nIRF were visualized microscopically. Scale bar in images is $20 \mu \mathrm{m}$. Treatment with DOPAL produced nIRF signals, suggesting the presence of quinoproteins. 
the current experiments we tested other metal ions, including $\mathrm{Fe}(\mathrm{II}), \mathrm{Mn}$ (II), and $\mathrm{Ca}(\mathrm{II}) . \mathrm{Cu}(\mathrm{II})$ was the most potent in terms of enhancing DOPAL-induced quinonization of AS (unpublished data). Collectively, the present findings suggest that the potential deleterious effects of $\mathrm{Cu}$ (II) at physiologically attainable concentrations are related to DOPAL more than to DA and might be ameliorated by antioxidant treatment.

A53T AS Is More Susceptible than Wild-Type AS to Quinonization by DOPAL. The extent of quinonization of AS by $\mathrm{Cu}(\mathrm{II})+$ DOPAL was about twice as great with the A53T mutant form of AS than with human WT AS. This finding suggests that, at least in the setting of $\mathrm{Cu}$ (II), neurons expressing mutant forms of AS may be more vulnerable to DOPAL-induced quinonization than neurons expressing WT AS.

DOPAL Quinonizes Numerous Intracellular Proteins; DA Does Not. In MO3.13 oligodendrocytes DOPAL, but not DA, resulted in the formation of numerous intracellular quinoproteins. Incubation of cells with hydrogen peroxide or in serum-free medium to evoke oxidative stress does not result in the formation of cellular quinoproteins (unpublished data). Therefore, DOPAL-induced intracellular protein quinonization does not seem to be the nonspecific result of oxidative stress. nIRF microscopy revealed myriad punctate sites of DOPAL-derived signals corresponding in position to nuclei, as well as large, high-intensity deposits of nIRF signals in extracellular fluid or remnants of necrotic cells. The identities of the quinoproteins are unknown but might be revealed by a proteomics technical approach.

We doubt that the lack of effect of dopamine on visualized intracellular quinoproteins was from the dopamine not being taken up into the cells. Glial cells express the cell membrane norepinephrine transporter and the extraneuronal transporter mediating the uptake-2 process (Takeda et al., 2002). Since dopamine is a better substrate for the norepinephrine transporter than is norepinephrine (Eisenhofer, 2001), it is reasonable to presume that dopamine was taken up. In separate experiments we measured intracellular dopamine in cultured oligodendrocytes incubated with dopamine. We detected a large amount of dopamine and little, if any, DOPAL in the cells (unpublished data), which we attribute to relatively little MAO activity in the cells. Although DOPAL evokes substantial neurotoxicity (Panneton et al., 2010), interferes with key catecholaminergic functions such as tyrosine hydroxylation and decarboxylation of DOPA to form dopamine (Jinsmaa et al., 2018), and evokes quinonization of numerous intracellular proteins, thus far there has been no demonstration that DOPAL-induced cytotoxicity is mediated by protein quinonization.

Implications and Conclusions. Protein modifications such as AS oligomerization and quinonization induced by DOPAL could result in functional abnormalities-e.g., decreased neurotransmitter synthesis, vesicular storage, and recycling (Goldstein et al., 2011a, 2013, 2017b, 2019) that increasingly challenge neuronal homeostasis during a long prodromal phase. The present results may have implications for disease-modification therapeutic strategies in conditions involving catecholaminergic neurodegeneration. Inhibition by NAC of protein modifications induced by DOPAL-Q may help explain the finding that in PD patients NAC improves scores on the Uniform Parkinson Disease Rating Scale and results of striatal dopaminergic neuroimaging (Monti et al., 2016, 2019).
A rational target for future experimental therapeutics may be the sequence of enzymatic oxidation of DA to form DOPAL via MAO and the spontaneous oxidation of DOPAL to form DOPAL-Q. In conclusion, of the two routes by which DA oxidation modifies AS and other proteins, that via DOPAL is more prominent.

\section{Acknowledgments}

We acknowledge the assistance of Abraham Corrales in the experiments involving immunofluorescence microsopy and Patti Sullivan in the experiments involving enzymatic oxidation of dopamine.

\section{Authorship Contributions}

Participated in research design: Jinsmaa, Sharabi, Goldstein. Conducted experiments: Jinsmaa, Isonaka.

Performed data analysis: Jinsmaa.

Wrote or contributed to the writing of the manuscript: Jinsmaa, Sharabi, Goldstein.

\section{References}

Anderson DG, Florang VR, Schamp JH, Buettner GR, and Doorn JA (2016) Antioxidant-mediated modulation of protein reactivity for 3,4-dihydroxyphenylacetaldehyde, a toxic dopamine metabolite. Chem Res Toxicol 29: 1098-1107.

Anderson DG, Mariappan SV, Buettner GR, and Doorn JA (2011) Oxidation of 3,4dihydroxyphenylacetaldehyde, a toxic dopaminergic metabolite, to a semiquinone radical and an ortho-quinone. J Biol Chem 286:26978-26986.

Asanuma M, Miyazaki I, and Ogawa N (2003) Dopamine- or L-DOPA-induced neurotoxicity: the role of dopamine quinone formation and tyrosinase in a model of Parkinson's disease. Neurotox Res 5:165-176.

Badillo-Ramírez I, Saniger JM, and Rivas-Arancibia S (2019) 5-S-cysteinyl-dopamine, a neurotoxic endogenous metabolite of dopamine: implications for Parkinson's disease. Neurochem Int 129:104514.

Banerjee K, Munshi S, Sen O, Pramanik V, Roy Mukherjee T, and Chakrabarti S (2014) Dopamine cytotoxicity involves both oxidative and nonoxidative pathways in SH-SY5Y cells: potential role of alpha-synuclein overexpression and proteasomal inhibition in the etiopathogenesis of Parkinson's disease. Parkinsons Dis 2014: 878935.

Blaschko H (1952) Amine oxidase and amine metabolism. Pharmacol Rev 4:415-458. Burbulla LF, Song P, Mazzulli JR, Zampese E, Wong YC, Jeon S, Santos DP, Blanz J, Obermaier CD, Strojny C, et al. (2017) Dopamine oxidation mediates mitochondrial and lysosomal dysfunction in Parkinson's disease. Science 357:1255-1261.

Burke WJ, Kumar VB, Pandey N, Panneton WM, Gan Q, Franko MW, O'Dell M, Li SW, Pan Y, Chung HD, et al. (2008) Aggregation of $\alpha$-synuclein by DOPAL, the monoamine oxidase metabolite of dopamine. Acta Neuropathol 115:193-203.

Burke WJ, Li SW, Williams EA, Nonneman R, and Zahm DS (2003) 3,4-Dihydroxyphenylacetaldehyde is the toxic dopamine metabolite in vivo: implications for Parkinson's disease pathogenesis. Brain Res 989:205-213.

Cagle BS, Crawford RA, and Doorn JA (2019) Biogenic aldehyde-mediated mechanisms of toxicity in neurodegenerative disease. Curr Opin Toxicol 13:16-21.

Carlsson A and Fornstedt B (1991) Possible mechanisms underlying the special vulnerability of dopaminergic neurons. Acta Neurol Scand Suppl 136:16-18.

Deas E, Cremades N, Angelova PR, Ludtmann MH, Yao Z, Chen S, Horrocks MH, Banushi B, Little D, Devine MJ, et al. (2016) Alpha-synuclein oligomers interact with metal ions to induce oxidative stress and neuronal death in Parkinson's disease. Antioxid Redox Signal 24:376-391.

Dell'Acqua S, Bacchella C, Monzani E, Nicolis S, Di Natale G, Rizzarelli E, and Casella L (2017) Prion peptides are extremely sensitive to copper induced oxidative stress. Inorg Chem 56:11317-11325.

Eisenhofer G (2001) The role of neuronal and extraneuronal plasma membrane transporters in the inactivation of peripheral catecholamines. Pharmacol Ther $\mathbf{9 1}$ : 35-62.

Follmer C, Coelho-Cerqueira E, Yatabe-Franco DY, Araujo GD, Pinheiro AS, Domont GB, and Eliezer D (2015) Oligomerization and membrane-binding properties of covalent adducts formed by the interaction of $\alpha$-synuclein with the toxic dopamine metabolite 3,4-dihydroxyphenylacetaldehyde (DOPAL). J Biol Chem 290: 27660-27679.

Goldstein DS, Holmes C, Kopin IJ, and Sharabi Y (2011a) Intra-neuronal vesicular uptake of catecholamines is decreased in patients with Lewy body diseases. J Clin Invest 121:3320-3330.

Goldstein DS, Jinsmaa Y, Sullivan P, and Sharabi Y (2017a) $N$-acetylcysteine prevents the increase in spontaneous oxidation of dopamine during monoamine oxidase inhibition in PC12 cells. Neurochem Res 42:3289-3295.

Goldstein DS, Kopin IJ, and Sharabi Y (2014) Catecholamine autotoxicity. Implications for pharmacology and therapeutics of Parkinson disease and related disorders. Pharmacol Ther 144:268-282.

Goldstein DS, Pekker MJ, Eisenhofer G, and Sharabi Y (2019) Computational modeling reveals multiple abnormalities of myocardial noradrenergic function in Lewy body diseases. JCI Insight 5:e130441.

Goldstein DS, Sullivan P, Holmes C, Kopin IJ, Basile MJ, and Mash DC (2011b) Catechols in post-mortem brain of patients with Parkinson disease. Eur J Neurol 18:703-710. 
Goldstein DS, Sullivan P, Holmes C, Kopin IJ, Sharabi Y, and Mash DC (2015) Decreased vesicular storage and aldehyde dehydrogenase activity in multiple system atrophy. Parkinsonism Relat Disord 21:567-572.

Goldstein DS, Sullivan P, Holmes C, Mash DC, Kopin IJ, and Sharabi Y (2017b) Determinants of denervation-independent depletion of putamen dopamine in Parkinson's disease and multiple system atrophy. Parkinsonism Relat Disord 35: 88-91.

Goldstein DS, Sullivan P, Holmes C, Miller GW, Alter S, Strong R, Mash DC, Kopin IJ, and Sharabi Y (2013) Determinants of buildup of the toxic dopamine metabolite DOPAL in Parkinson's disease. J Neurochem 126:591-603.

Gustafsson G, Lindström V, Rostami J, Nordström E, Lannfelt L, Bergström J, Ingelsson M, and Erlandsson A (2017) Alpha-synuclein oligomer-selective antibodies reduce intracellular accumulation and mitochondrial impairment in alphasynuclein exposed astrocytes. J Neuroinflammation 14:241

Hasegawa T, Matsuzaki-Kobayashi M, Takeda A, Sugeno N, Kikuchi A, Furukawa K Perry G, Smith MA, and Itoyama Y (2006) $\alpha$-Synuclein facilitates the toxicity of oxidized catechol metabolites: implications for selective neurodegeneration in Parkinson's disease. FEBS Lett 580:2147-2152.

Hastings TG (2009) The role of dopamine oxidation in mitochondrial dysfunction: implications for Parkinson's disease. J Bioenerg Biomembr 41:469-472.

Herrera A, Muñoz P, Steinbusch HWM, and Segura-Aguilar J (2017) Are dopamine oxidation metabolites involved in the loss of dopaminergic neurons in the nigrostriatal system in Parkinson's disease? ACS Chem Neurosci 8:702-711.

Hornykiewicz O (1966) Dopamine (3-hydroxytyramine) and brain function. Pharmacol Rev 18:925-964.

Huenchuguala S, Sjödin B, Mannervik B, and Segura-Aguilar J (2019) Novel alphasynuclein oligomers formed with the aminochrome-glutathione conjugate are not neurotoxic. Neurotox Res 35:432-440.

Jana S, Sinha M, Chanda D, Roy T, Banerjee K, Munshi S, Patro BS, and Chakrabarti S (2011) Mitochondrial dysfunction mediated by quinone oxidation products of dopamine: implications in dopamine cytotoxicity and pathogenesis of Parkinson's disease. Biochim Biophys Acta 1812:663-673.

Jinsmaa Y, Sharabi Y, Sullivan P, Isonaka R, and Goldstein DS (2018) 3,4-Dihydroxyphenylacetaldehyde-induced protein modifications and their mitigation by $N$-acetylcysteine. J Pharmacol Exp Ther 366:113-124.

Jinsmaa Y, Sullivan P, Gross D, Cooney A, Sharabi Y, and Goldstein DS (2014) Divalent metal ions enhance DOPAL-induced oligomerization of alpha-synuclein. Neurosci Lett 569:27-32.

Lee H, Dellatore SM, Miller WM, and Messersmith PB (2007) Mussel-inspired surface chemistry for multifunctional coatings. Science 318:426-430.

Lee HJ, Baek SM, Ho DH, Suk JE, Cho ED, and Lee SJ (2011) Dopamine promotes formation and secretion of non-fibrillar alpha-synuclein oligomers. Exp Mol Med 43:216-222.

Leong SL, Cappai R, Barnham KJ, and Pham CL (2009) Modulation of $\alpha$-synuclein aggregation by dopamine: a review. Neurochem Res 34:1838-1846.

Linsenbardt AJ, Breckenridge JM, Wilken GH, and Macarthur H (2012) Dopaminochrome induces caspase-independent apoptosis in the mesencephalic cell line, MN9D. J Neurochem 122:175-184.

Linsenbardt AJ, Wilken GH, Westfall TC, and Macarthur H (2009) Cytotoxicity of dopaminochrome in the mesencephalic cell line, MN9D, is dependent upon oxidative stress. Neurotoxicology 30:1030-1035.

Mattammal MB, Haring JH, Chung HD, Raghu G, and Strong R (1995) An endogenous dopaminergic neurotoxin: implication for Parkinson's disease. Neurodegeneration 4:271-281.

Mazzulli JR, Armakola M, Dumoulin M, Parastatidis I, and Ischiropoulos H (2007) Cellular oligomerization of $\alpha$-synuclein is determined by the interaction of oxidized catechols with a C-terminal sequence. J Biol Chem 282:31621-31630.

Mazzulli JR, Mishizen AJ, Giasson BI, Lynch DR, Thomas SA, Nakashima A, Nagatsu T, Ota A, and Ischiropoulos H (2006) Cytosolic catechols inhibit $\alpha$-synuclein aggregation and facilitate the formation of intracellular soluble oligomeric intermediates. $J$ Neurosci 26:10068-10078.

Montes S, Rivera-Mancia S, Diaz-Ruiz A, Tristan-Lopez L, and Rios C (2014) Copper and copper proteins in Parkinson's disease. Oxid Med Cell Longev 2014:147251.

Monti DA, Zabrecky G, Kremens D, Liang TW, Wintering NA, Bazzan AJ, Zhong L, Bowens BK, Chervoneva I, Intenzo C, et al. (2019) N-acetyl cysteine is associated with dopaminergic improvement in Parkinson's disease. Clin Pharmacol Ther 106: 884-890.

Monti DA, Zabrecky G, Kremens D, Liang TW, Wintering NA, Cai J, Wei X, Bazzan AJ, Zhong L, Bowen B, et al. (2016) N-Acetyl cysteine may support dopamine neurons in Parkinson's disease: preliminary clinical and cell line data. PLoS One 11:e0157602.

Montine TJ, Picklo MJ, Amarnath V, Whetsell WO Jr, and Graham DG (1997) Neurotoxicity of endogenous cysteinylcatechols. Exp Neurol 148:26-33.
Mor DE, Daniels MJ, and Ischiropoulos H (2019) The usual suspects, dopamine and alpha-synuclein, conspire to cause neurodegeneration. Mov Disord 34:167-179.

Mor DE, Tsika E, Mazzulli JR, Gould NS, Kim H, Daniels MJ, Doshi S, Gupta P, Grossman JL, Tan VX, et al. (2017) Dopamine induces soluble $\alpha$-synuclein oligomers and nigrostriatal degeneration. Nat Neurosci 20:1560-1568.

Muñoz P, Cardenas S, Huenchuguala S, Briceño A, Couve E, Paris I, and SeguraAguilar J (2015) DT-diaphorase prevents aminochrome-induced alpha-synuclein oligomer formation and neurotoxicity. Toxicol Sci 145:37-47.

Nagatsu T (1997) Isoquinoline neurotoxins in the brain and Parkinson's disease. Neurosci Res 29:99-111.

Panneton WM, Kumar VB, Gan Q, Burke WJ, and Galvin JE (2010) The neurotoxicity of DOPAL: behavioral and stereological evidence for its role in Parkinson disease pathogenesis. PLoS One 5:e15251.

Paris I, Lozano J, Perez-Pastene C, Muñoz P, and Segura-Aguilar J (2009) Molecular and neurochemical mechanisms in PD pathogenesis. Neurotox Res 16:271-279.

Pham CL, Leong SL, Ali FE, Kenche VB, Hill AF, Gras SL, Barnham KJ, and Cappai $\mathrm{R}$ (2009) Dopamine and the dopamine oxidation product 5,6-dihydroxylindole promote distinct on-pathway and off-pathway aggregation of $\alpha$-synuclein in a pHdependent manner. J Mol Biol 387:771-785.

Plotegher N, Berti G, Ferrari E, Tessari I, Zanetti M, Lunelli L, Greggio E, Bisaglia M, Veronesi M, Girotto S, et al. (2017) DOPAL derived alpha-synuclein oligomers impair synaptic vesicles physiological function. Sci Rep 7:40699.

Pukass K and Richter-Landsberg C (2014) Oxidative stress promotes uptake, accumulation, and oligomerization of extracellular $\alpha$-synuclein in oligodendrocytes. $J$ Mol Neurosci 52:339-352.

Rees JN, Florang VR, Eckert LL, and Doorn JA (2009) Protein reactivity of 3,4dihydroxyphenylacetaldehyde, a toxic dopamine metabolite, is dependent on both the aldehyde and the catechol. Chem Res Toxicol 22:1256-1263.

Saha S, Khan MAI, Mudhara D, and Deep S (2018) Tuning the balance between fibrillation and oligomerization of $\alpha$-synuclein in the presence of dopamine. ACS Omega 3:14213-14224.

Segura-Aguilar J (2017) On the role of endogenous neurotoxins and neuroprotection in Parkinson's disease. Neural Regen Res 12:897-901.

Segura-Aguilar J (2019) On the role of aminochrome in mitochondrial dysfunction and endoplasmic reticulum stress in Parkinson's disease. Front Neurosci 13:271.

Spillantini MG, Schmidt ML, Lee VM, Trojanowski JQ, Jakes R, and Goedert M (1997) $\alpha$-Synuclein in Lewy bodies. Nature 388:839-840.

Storch A, Ott S, Hwang YI, Ortmann R, Hein A, Frenzel S, Matsubara K, Ohta S, Wolf HU, and Schwarz J (2002) Selective dopaminergic neurotoxicity of isoquinoline derivatives related to Parkinson's disease: studies using heterologous expression systems of the dopamine transporter. Biochem Pharmacol 63:909-920.

Surmeier DJ, Guzman JN, Sanchez-Padilla J, and Goldberg JA (2011) The origins of oxidant stress in Parkinson's disease and therapeutic strategies. Antioxid Redox Signal 14:1289-1301.

Takeda H, Inazu M, and Matsumiya T (2002) Astroglial dopamine transport is mediated by norepinephrine transporter. Naunyn Schmiedebergs Arch Pharmacol 366:620-623.

Tong J, Fitzmaurice PS, Ang LC, Furukawa Y, Guttman M, and Kish SJ (2004) Brain dopamine-stimulated adenylyl cyclase activity in Parkinson's disease, multiple system atrophy, and progressive supranuclear palsy. Ann Neurol 55:125-129.

Tu PH, Galvin JE, Baba M, Giasson B, Tomita T, Leight S, Nakajo S, Iwatsubo T, Trojanowski JQ, and Lee VM (1998) Glial cytoplasmic inclusions in white matter oligodendrocytes of multiple system atrophy brains contain insoluble $\alpha$-synuclein. Ann Neurol 44:415-422.

Wakabayashi K, Yoshimoto M, Tsuji S, and Takahashi H (1998) $\alpha$-Synuclein immunoreactivity in glial cytoplasmic inclusions in multiple system atrophy. Neurosci Lett 249:180-182.

Werner-Allen JW, DuMond JF, Levine RL, and Bax A (2016) Toxic dopamine metabolite DOPAL forms an unexpected dicatechol pyrrole adduct with lysines of $\alpha$-synuclein. Angew Chem Int Ed Engl 55:7374-7378.

Werner-Allen JW, Levine RL, and Bax A (2017) Superoxide is the critical driver of DOPAL autoxidation, lysyl adduct formation, and crosslinking of $\alpha$-synuclein Biochem Biophys Res Commun 487:281-286.

Werner-Allen JW, Monti S, DuMond JF, Levine RL, and Bax A (2018) Isoindole linkages provide a pathway for DOPAL-mediated cross-linking of $\alpha$-synuclein. Biochemistry 57:1462-1474.

Winner B, Jappelli R, Maji SK, Desplats PA, Boyer L, Aigner S, Hetzer C, Loher T, Vilar M, Campioni S, et al. (2011) In vivo demonstration that $\alpha$-synuclein oligomers are toxic. Proc Natl Acad Sci USA 108:4194-4199.

Address correspondence to: Dr. David S. Goldstein, National Institutes of Health, 10 Center Drive, Bldg. 10, Rm. 8N260, Bethesda, MD 20892-1620. E-mail: goldsteind@ninds.nih.gov 